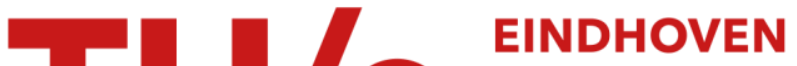 \\ UNIVERSITY OF \\ TECHNOLOGY
}

\section{Atomic layer deposition of cobalt phosphate from cobaltocene, trimethylphosphate, and $\mathrm{O} 2$ plasma}

Citation for published version (APA):

Di Palma, V., Knoops, H. C. M., Kessels, W. M. M., \& Creatore, M. (2020). Atomic layer deposition of cobalt phosphate from cobaltocene, trimethylphosphate, and O2 plasma. Journal of Vacuum Science and Technology A: Vacuum, Surfaces, and Films, 38(2), [022416]. https://doi.org/10.1116/1.5143896

\section{Document license:}

TAVERNE

DOI:

10.1116/1.5143896

Document status and date:

Published: 01/03/2020

\section{Document Version:}

Publisher's PDF, also known as Version of Record (includes final page, issue and volume numbers)

\section{Please check the document version of this publication:}

- A submitted manuscript is the version of the article upon submission and before peer-review. There can be important differences between the submitted version and the official published version of record. People interested in the research are advised to contact the author for the final version of the publication, or visit the $\mathrm{DOI}$ to the publisher's website.

- The final author version and the galley proof are versions of the publication after peer review.

- The final published version features the final layout of the paper including the volume, issue and page numbers.

Link to publication

\section{General rights}

Copyright and moral rights for the publications made accessible in the public portal are retained by the authors and/or other copyright owners and it is a condition of accessing publications that users recognise and abide by the legal requirements associated with these rights.

- Users may download and print one copy of any publication from the public portal for the purpose of private study or research.

- You may not further distribute the material or use it for any profit-making activity or commercial gain

- You may freely distribute the URL identifying the publication in the public portal.

If the publication is distributed under the terms of Article 25fa of the Dutch Copyright Act, indicated by the "Taverne" license above, please follow below link for the End User Agreement:

www.tue.nl/taverne

Take down policy

If you believe that this document breaches copyright please contact us at:

openaccess@tue.nl

providing details and we will investigate your claim. 


\section{Atomic layer deposition of cobalt phosphate from cobaltocene, trimethylphosphate, and $\mathrm{O}_{2}$ plasma}

Cite as: J. Vac. Sci. Technol. A 38, 022416 (2020); https://doi.org/10.1116/1.5143896

Submitted: 06 January 2020 . Accepted: 05 February 2020 . Published Online: 19 February 2020

Valerio Di Palma (D), Harm C. M. Knoops (D), Wilhelmus M. M. (Erwin) Kessels (D), and Mariadriana Creatore (iD)

\section{COLLECTIONS}

Paper published as part of the special topic on Special Topic Collection on Atomic Layer Deposition (ALD) Note: This paper is part of the 2020 Special Topic Collection on Atomic Layer Deposition (ALD).
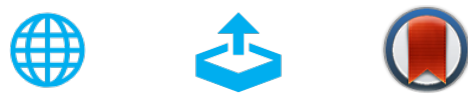

\section{ARTICLES YOU MAY BE INTERESTED IN}

Atomic layer deposition of molybdenum oxide from $\left(\mathrm{N}^{\mathrm{t}} \mathrm{Bu}\right)_{2}\left(\mathrm{NMe}_{2}\right)_{2} \mathrm{Mo}$ and $\mathrm{O}_{2}$ plasma Journal of Vacuum Science \& Technology A 34, 01 A103 (2016); https://doi.org/10.1116/1.4930161

Infrared and optical emission spectroscopy study of atmospheric pressure plasma-enhanced spatial ALD of $\mathrm{Al}_{2} \mathrm{O}_{3}$

Applied Physics Letters 115, 083101 (2019); https://doi.org/10.1063/1.5113753

Atomic layer deposition of silicon-based dielectrics for semiconductor manufacturing: Current status and future outlook

Journal of Vacuum Science \& Technology A 37, 060904 (2019); https://doi.org/10.1116/1.5113631

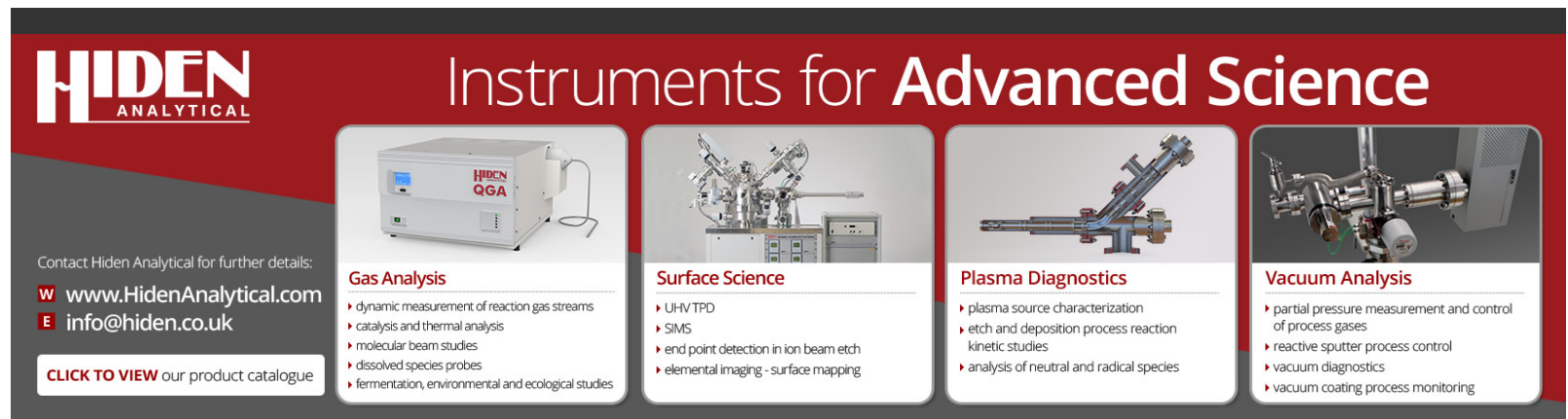




\title{
Atomic layer deposition of cobalt phosphate from cobaltocene, trimethylphosphate, and $\mathrm{O}_{2}$ plasma
}

\author{
Cite as: J. Vac. Sci. Technol. A 38, 022416 (2020); doi: 10.11 16/1.5143896 \\ Submitted: 6 January 2020 - Accepted: 5 February 2020 . \\ Published Online: 19 February 2020
}

Valerio Di Palma, $^{1, a)}$ (D) Harm C. M. Knoops, ${ }^{1,2}$ (D) Wilhelmus M. M. (Erwin) Kessels, ${ }^{1}$ (D) and Mariadriana Creatore

\begin{abstract}
AFFILIATIONS
${ }^{1}$ Department of Applied Physics, Eindhoven University of Technology, P.O. Box 513, 5600 MB Eindhoven, The Netherlands

${ }^{2}$ Oxford Instruments Plasma Technology, North End, Bristol BS49 4AP, United Kingdom
\end{abstract}

Note: This paper is part of the 2020 Special Topic Collection on Atomic Layer Deposition (ALD).

${ }^{a}$ Electronic mail: $v$.d.palma@tue.nl

\begin{abstract}
Electrodeposited cobalt phosphate has been reported in the literature as a robust alternative to noble metal-based electrocatalysts for the $\mathrm{O}_{2}$ evolution reaction. In parallel, atomic layer deposition (ALD) has been acknowledged as a key technology for the preparation of thin films for energy applications. With the present work, the authors have addressed the preparation of cobalt phosphate thin films by a plasma-assisted ALD process. The process developed consists of cobaltocene (step A) and trimethyl phosphate (step C) exposures alternated by $\mathrm{O}_{2}$ plasma (steps B and D) in an ABCD fashion. The process shows a linear growth with a growth per cycle of $1.12 \pm 0.05 \AA$ at $300^{\circ} \mathrm{C}$ and no nucleation delay. The ALD saturation behavior has been demonstrated for each dosing step, and the process shows minimal inhomogeneity on $100 \mathrm{~mm}$ diameter wafers in terms of film thickness $(<1.0 \%)$ and refractive index $(<0.5 \%)$. The chemical characterization of the layers deposited shows that the composition is close to the stoichiometric $\left(\mathrm{Co}_{3.1} \mathrm{P}_{2} \mathrm{O}_{8.3}\right.$ for a deposition temperature of $\left.200^{\circ} \mathrm{C}\right)$ and the oxidation states of cobalt and phosphorus and agrees with those reported in the literature. The cobalt-to-phosphorous ratio has been found to correlate with the values of absorption coefficient $(k)$ and refractive index $(n)$ of the layers. Furthermore, the authors have gained insights into the surface reactions occurring during each ALD step by quadrupole mass spectrometry investigation. The results suggest that cobaltocene undergoes associative adsorption and the cyclopentadienyl ligands are removed during subsequent $\mathrm{O}_{2}$ plasma exposure. Moreover, the authors have indirectly identified cyclopentadienone as an intermediate of the oxidation and removal of cyclopentadienyl ligand. On the other hand, the trimethyl phosphate dosing is characterized by chemisorption via the elimination of methanol.
\end{abstract}

Published under license by AVS. https://doi.org/10.1116/1.5143896

\section{INTRODUCTION}

Electricity storage into chemicals is an attractive solution to the challenge of the intermittency of renewable energy sources, such as wind and solar. The most known example is water splitting run on solar light-harvested electricity. ${ }^{1-5}$ The cobalt phosphate (CoPi)-based electrocatalyst is an earth-abundant and cost-effective alternative to noble metal-based electrocatalysts, acknowledged since a few years for the good performance toward $\mathrm{O}_{2}$ evolution reaction (OER) both in neutral and high $p \mathrm{H}^{6-10} \mathrm{CoPi}$ is known to be a bulk electrocatalyst, i.e., the current density produced for OER is proportional to the volume of the catalyst indicating that the Co centers present in the bulk also participate in the OER., Moreover, CoPi has been applied as a cocatalyst in combination with a photoelectrode for the integration in photoelectrochemical (PEC) cells for water splitting. ${ }^{10}$ Further contribution to the design of the properties of CoPi can be given by atomic layer deposition (ALD), a thin film deposition method based on the cyclic sequential dosing of vapor-phase reactants. ALD is a key technology for the preparation, nanostructuring, and engineering of thin films for energy applications, ranging from solar cell technologies to solid-state batteries, water splitting devices, and fuel cells. ${ }^{11,12}$ The characteristic features of ALD include excellent control of the thickness at the atomic level, good uniformity and conformality, and high control over the material composition. ${ }^{13}$

Recently, we have demonstrated the synthesis of CoPi by ALD and showed that the developed electrocatalyst is active toward OER and outperforms traditional electrodeposited films. ${ }^{14}$ Moreover, the process developed enabled tuning of the Co-to-P ratio by combining the CoPi process with extra ALD cycles of $\mathrm{CoO}_{\mathrm{x}}$. The latter approach has led to the improvement of the performance of the electrocatalyst. ${ }^{14}$ 
After electrocatalysis, it is expected that $\mathrm{CoPi}$, as well as other transition metal phosphates prepared by ALD, ${ }^{15,16}$ can also have interesting applications in thin film lithium ion batteries. For example, $\mathrm{LiCoPO}_{4}$ has already been reported ${ }^{17-19}$ for that application.

The ALD of phosphates has been reported for several metals, such as iron, ${ }^{15}$ aluminum, ${ }^{20,21}$ calcium, ${ }^{22}$ lithium, ${ }^{23,24}$ titanium, ${ }^{16,20,25}$ lanthanum, ${ }^{26}$ and zinc. ${ }^{27}$ The incorporation of phosphate generally involves the use of trimethyl phosphate (TMP) or triethyl phosphate as a precursor and either $\mathrm{H}_{2} \mathrm{O}, \mathrm{O}_{3}$, or a combination of them as coreactant. TMP has also been reported in the literature as a plasma-activated precursor, i.e., via TMP plasma polymerization. ${ }^{16,21,27}$ Very recently, this approach has been used for the preparation of cobalt phosphate/phosphide and iron phosphate/ phosphide layers, applied as bifunctional electrocatalysts for the OER and the hydrogen evolution reaction (HER). ${ }^{28}$

In this paper, we address the process development of ALD of $\mathrm{CoPi}$ as well as the characterization of the material in terms of optochemical properties in view of its application. Moreover, we infer the surface reactions taking place during the ALD steps to deduce the effect of those on the overall ALD process characteristics. CoPi is prepared by combining ALD of $\mathrm{CoO}_{\mathrm{x}}$ from cobaltocene and $\mathrm{O}_{2}$ plasma as reactant, with cycles of TMP followed by $\mathrm{O}_{2}$ plasma exposure, according to an $A B C D$ process scheme. For the $\mathrm{CoO}_{\mathrm{x}}$ part $(\mathrm{AB}$ steps), we adopted the process reported by Donders et al. ${ }^{29}$ In contrast, the adoption of TMP dosing followed by $\mathrm{O}_{2}$ plasma (CD steps) has not been addressed yet in the literature.

\section{EXPERIMENT}

Atomic layer deposition was performed in a home-built reactor described elsewhere. ${ }^{30,31}$ The pumping system, consisting of a turbo pump connected to a rotary pump, enabled us to keep the base pressure of the reactor $<10^{-6}$ mbar. The reactor was equipped with a remote inductively coupled plasma (ICP) source with a power supply operating at $13.56 \mathrm{MHz}$. The walls of the chamber were heated to $100^{\circ} \mathrm{C}$ while the substrate holder, suitable for fitting a $100-\mathrm{mm}$ diameter substrate, was heated to $300^{\circ} \mathrm{C}$, unless specified otherwise. Cobaltocene $\left(\mathrm{CoCp}_{2}, 98 \%\right.$ purity) and TMP $\left[\left(\mathrm{CH}_{3} \mathrm{O}\right)_{3} \mathrm{PO}, 97 \%\right.$ purity], both purchased from Sigma-Aldrich, were selected as precursors for the process. $\mathrm{CoCp}_{2}$ was contained in a stainless steel cylindrical container heated to $80^{\circ} \mathrm{C}$. Argon gas ( $>99.999 \%$ purity) was used to carry $\mathrm{CoCp}_{2}$ vapor from the container to the reactor through a line heated to $100^{\circ} \mathrm{C}$. TMP was vapor drawn to the chamber, heating its container to $50^{\circ} \mathrm{C}$ and the line to the reactor to $70^{\circ} \mathrm{C}$. For the $\mathrm{O}_{2}$ plasma, used as reactant in the process, $\mathrm{O}_{2}$ gas $(>99.999 \%$ purity) was flowed through the plasma source for $4 \mathrm{~s}$ to stabilize the pressure to $8.0 \times 10^{-3} \mathrm{mbar}$ and then plasma was ignited by providing $100 \mathrm{~W}$ of power to the ICP source.

The default ABCD ALD process used for the deposition of $\mathrm{CoPi}$, upon investigation of the self-limiting behavior, is illustrated in Fig. 1. The process starts by flowing argon, in order to stabilize the pressure inside the chamber to $2.0 \times 10^{-2} \mathrm{mbar}$, and then dosing $\mathrm{CoCp}_{2}$ for $2 \mathrm{~s}$ (step A) by diverting Ar through the CoCp container. Subsequently, Ar is flowed for $3 \mathrm{~s}$ for purging and the reactor is pumped down for $3 \mathrm{~s}$. Afterward, $\mathrm{O}_{2}$ plasma is ignited for $5 \mathrm{~s}$ (step B). Next, TMP is dosed for $0.6 \mathrm{~s}$ (step C) followed by a

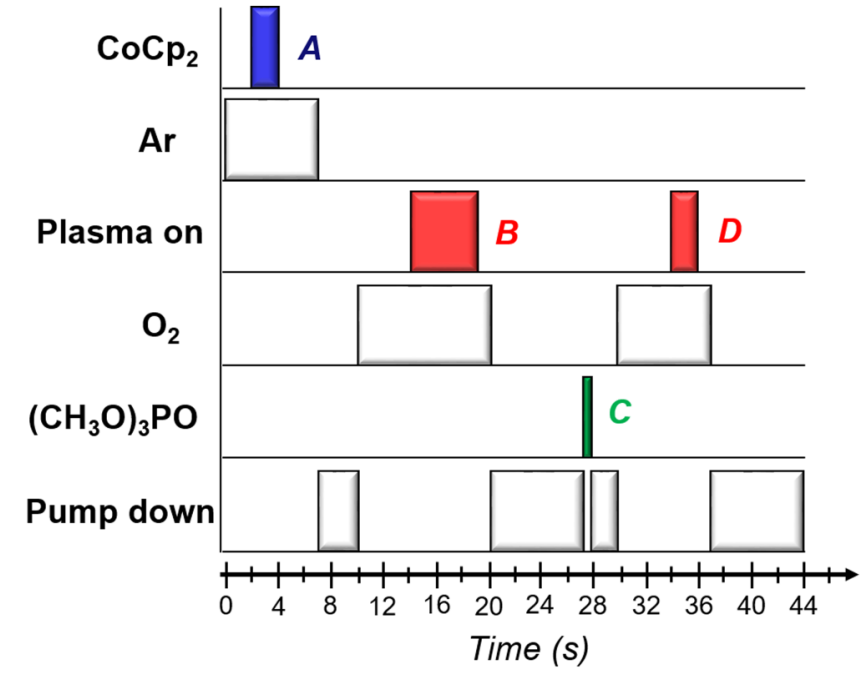

$\begin{array}{lll}\text { Arpressure: } & \mathrm{O}_{2} \text { pressure: } & \text { Plasma power: } \\ 2.0 \times 10^{-2} \mathrm{mbar} & 8.0 \times 10^{-3} \mathrm{mbar} & 100 \mathrm{~W}\end{array}$

FIG. 1. Scheme of the default ALD process used for the deposition of the CoPi.

pumping down step of $2 \mathrm{~s}$. Subsequently, $\mathrm{O}_{2}$ plasma is ignited for $2 \mathrm{~s}$ (step D). Each one of the two $\mathrm{O}_{2}$ plasma steps (B and D) is followed by $7 \mathrm{~s}$ of pumping down, the time that is sufficient to reach the base pressure of $10^{-6} \mathrm{mbar}$.

c-Si(100) was used as a substrate for both the in situ characterization of the process and the ex situ analysis of the deposited layers. Before each deposition, a cleaning step of $5 \mathrm{~min}$ was performed by means of $\mathrm{O}_{2}$ plasma, removing adventitious carbon from the silicon surface and establishing a $\mathrm{SiO}_{2}$-terminated surface.

Spectroscopic ellipsometry (SE) was performed for evaluation of growth per cycle (GPC), analysis of the uniformity of the process, and characterization of the optical properties.

In situ SE was performed using a Woollam M-2000 ellipsometer with an angle of incidence of $70^{\circ}$ and fitting the data with the CompleteEASE software. The results were fitted in the spectral range between 1.3 and $4.5 \mathrm{eV}$ using a model consisting of the Cauchy dispersion formula for the real part of the complex refractive index $(n)$ and an exponential decay function for the imaginary part $(k)$. The fitting was performed starting from the last measurement, corresponding to the largest thickness of the layer and then fitting the data backward in thickness. For the determination of the saturation curves, the process was characterized by depositing 100 ALD cycles on a CoPi seed layer previously prepared by 200 ALD cycles, according to the default process. Then, in order to reduce any possible influence of the substrate on the initial stages of the growth, only the last 50 cycles were taken into account for the determination of the GPC by linear fitting of the thickness.

The film's uniformity was studied ex situ by a Woollam M-2000 ellipsometer, which allows the automating mapping of the sample with an angle of incidence of $65^{\circ}$, measuring in the spectral range between 1.24 and $3.34 \mathrm{eV}$. The uniformity of the film was 
evaluated using a $100-\mathrm{mm}$ silicon wafer as substrate and preparing the sample by $300 \mathrm{ALD}$ cycles at $300^{\circ} \mathrm{C}$. Subsequently, the mapping was performed on 64 different spots of the sample in order to determine the variation of thickness and $n$ at $1.96 \mathrm{eV}$, using the above-mentioned model to fit the results. To avoid any possible deviation due to the handling of the sample, a 5-mm circular section from the edge was excluded from the measurement.

The ALD process window and the optical properties of the layers were studied ex situ using a UV-VIS ellipsometer (Woollam M-2000) mounted on an automatic stage for multiangle measurements at $65^{\circ}, 70^{\circ}$, and $75^{\circ}$ and acquiring in the spectral range between $1.24 \mathrm{eV}(1000 \mathrm{~nm})$ and $6.2 \mathrm{eV}(200 \mathrm{~nm})$. The samples were prepared at 100,200 , and $300{ }^{\circ} \mathrm{C}$ by 300 ALD cycles. For the determination of the optical properties of the layers in the UV-VIS region of the spectrum, fitting of the SE data was performed using a Tauc-Lorentz oscillator; in order to achieve a proper fit of the absorption peak in the UV region, minimizing the mean square error (MSE) in the spectral range between 1.24 and $6.2 \mathrm{eV}$. The choice of the fitting model was dictated by the fact that the Cauchy dispersion formula was not able to describe the absorption in the UV region.

For the elemental characterization of the layers, Rutherford backscattering spectroscopy (RBS) and elastic recoil detection (ERD) were carried out by applying a $2 \mathrm{MeV} \mathrm{He}^{+}$beam for both methods.

X-ray photoemission spectroscopy (XPS) studies were carried out on a Thermo Scientific K-Alpha system, equipped with a monochromatic $\mathrm{Al} \mathrm{K} \alpha \mathrm{X}$-ray source at $1486.6 \mathrm{eV}$. The $\mathrm{C} 1$ s peak of the adventitious carbon was used as reference, by setting its binding energy at $285.0 \mathrm{eV} .^{32,33}$ The crystallinity of the CoPi film was studied by $\mathrm{X}$-ray diffraction in grazing incidence mode (GI-XRD) by a PANalytical X'Pert Pro MRD system, using $\mathrm{Cu} \mathrm{K} \alpha$ $\mathrm{X}$-rays $\left(\lambda=1.54 \AA\right.$ ) in the range between $15^{\circ}$ and $75^{\circ}$.

Scanning electron microscopy (SEM) images were obtained with a Supra 40 (Carl Zeiss AG) microscope using an in-lens detector and accelerating voltage of $3 \mathrm{kV}$ for the cross section and $5 \mathrm{kV}$ for the top view.

To generate insights into the surface reactions occurring during each ALD step, time-resolved quadrupole mass spectrometry (QMS) measurements were carried out using a Pfeiffer Vacuum Prisma QME-200 connected to the ALD chamber measuring in the range of mass-to-charge ratio $(\mathrm{m} / \mathrm{z})$ from 1 to 100 . The mass spectrometer was equipped with a channeltron detector and an electron source operating at $70 \mathrm{eV}$ for the ionization of the gas species collected from the ALD reactor. The pressure in the mass spectrometer was maintained below $10^{-5}$ mbar by differential pumping using a turbomolecular pump. The ALD process used for the QMS measurements was modified by increasing all the dosing times by a factor of 2 in order to have a better resolution in time of the ALD process. Then, the data of 25 ALD cycles were collected and averaged in order to increase the signal-to-noise ratio and then normalized by the highest current density for each $m / z$. The process was also studied by means of a multipulse approach, which allows us to identify and distinguish between the saturation behavior characteristic of the reactants and the by-products. ${ }^{34}$ For the multipulse approach, the ALD process has been modified by repeating three times the dosing step studied, following the scheme
"AAA-BBB-C-D" when addressing the first half of the ALD process and the scheme "A-B-CCC-DDD" for the second half.

It should be noticed that the reaction products from the wall of the reactor can provide a major contribution to the overall signal. Moreover, the trend in time of the signal detected can be influenced by pressure variations; therefore, the $\mathrm{m} / z$ of $\mathrm{Ar}$ and $\mathrm{O}_{2}$ were taken into account as reference when drawing conclusions about the $\mathrm{CoCp}_{2}$ dosing and the $\mathrm{O}_{2}$ plasma step, respectively.

\section{RESULTS AND DISCUSSION}

\section{A. ALD process}

The average GPC of the ALD process was determined by performing multiple depositions. The process showed linear growth and no nucleation delay (see Fig. S1 in the supplementary material $^{56}$ ). The average GPC of the process based on seven measurements was $1.12 \AA$ with a standard deviation of $0.05 \AA$.

To investigate whether the process exhibits a self-limiting growth behavior, the saturation curve for each dosing step of the ALD process was investigated by varying the dosing time of each precursor or coreactant independently. The data reported in Fig. 2 show the GPC measured as a function of the dosing times. The four dosing steps are self-limiting and the dosing times used for the default deposition of $\mathrm{CoPi}$, i.e., $2 \mathrm{~s}$ for $\mathrm{CoCp}_{2}, 5 \mathrm{~s}$ for the first $\mathrm{O}_{2}$ plasma step, $0.6 \mathrm{~s}$ for TMP, and $2 \mathrm{~s}$ for the second $\mathrm{O}_{2}$ plasma step, are all within the saturation regime. The ALD process without TMP dosing leads to the deposition of a $\mathrm{CoO}_{\mathrm{x}}$ layer, with a GPC of $0.49 \pm 0.08 \AA$ [see Fig. 2(c)], in agreement with the report by Donders et al. ${ }^{29}$ On the other hand, the GPC of a $\mathrm{PO}_{\mathrm{x}}$ layer without cobalt dosing is negligible $[0.01 \pm 0.08 \AA$, see Fig. 2(a)], pointing out that the presence of a cobalt oxide terminated surface plays a role in the surface reactions of TMP. This is in line with earlier literature on ALD of iron phosphate, where TMP dosing did not lead to film growth in the absence of the iron oxide step, ${ }^{15}$ although in that case, differently from our work, a combination of $\mathrm{H}_{2} \mathrm{O}$ and $\mathrm{O}_{3}$ has been used as a coreactant.

Next, we report on process uniformity in terms of thickness [Fig. 3(a)] and $n$ at $1.96 \mathrm{eV}$ [Fig. 3(b)] on a $100-\mathrm{mm}$ c-Si substrate. The black dots in the figure show the positions where the measurements were taken. A measure of inhomogeneity of the layer can be calculated by applying the following formula:

$$
\text { Inhomogeneity } \%=\left(\frac{a_{\text {stdv }}}{a_{\text {avg }}}\right) \times 100,
$$

where $a_{\text {stdv }}$ and $a_{\text {avg }}$ are the standard deviation and the average of the parameter investigated, respectively. The thickness ranges from 33.3 to $34.5 \mathrm{~nm}$, with values that can be translated into an inhomogeneity of only $1.0 \%$. The value of $n$ ranges from 1.74 to 1.78 with an inhomogeneity of only $0.5 \%$. The variation of both $n$ and thickness seems to follow the same trend, with a decrease in the values going from the top right to the bottom left of the sample. No clear correlation has been found between this variation and the parameters typically influencing uniformity, e.g., a gradient in the table temperature or a specific direction of the injection point of the precursors. 

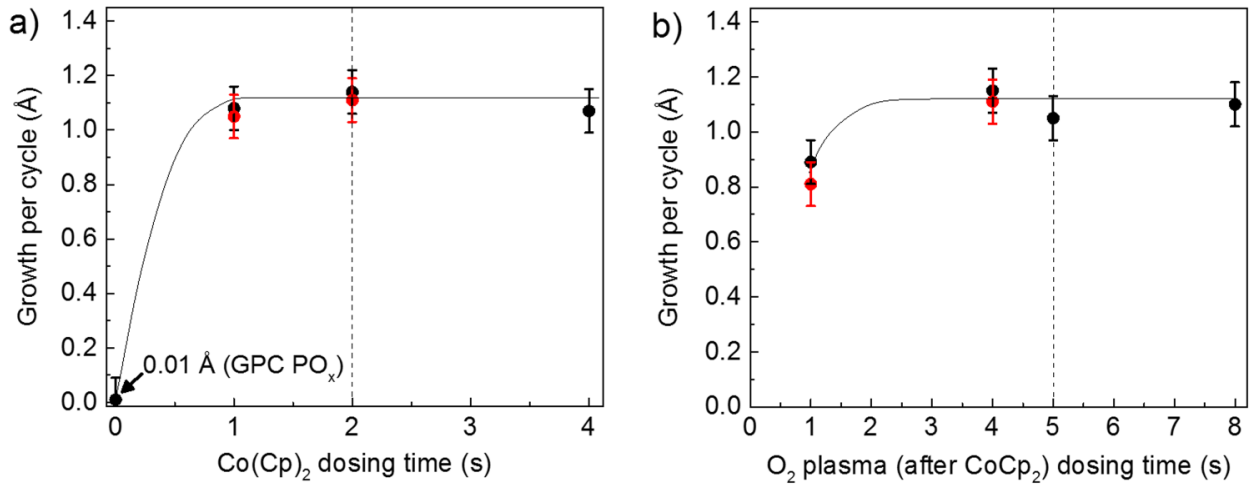

FIG. 2. Saturation curves of the four ALD steps used for the deposition of CoPi: (a) $\mathrm{CoCp}_{2}$ dosing, (b) $\mathrm{O}_{2}$ plasma step after $\mathrm{CoCp}_{2}$ dosing, (c) TMP dosing, and (d) $\mathrm{O}_{2}$ plasma step after TMP dosing. Data points reported in different colors belong to two different series of measurements. The two values reported for $0 \mathrm{~s}$ of dosing of $\mathrm{CoCp}_{2}$ and of TMP indicate the GPC
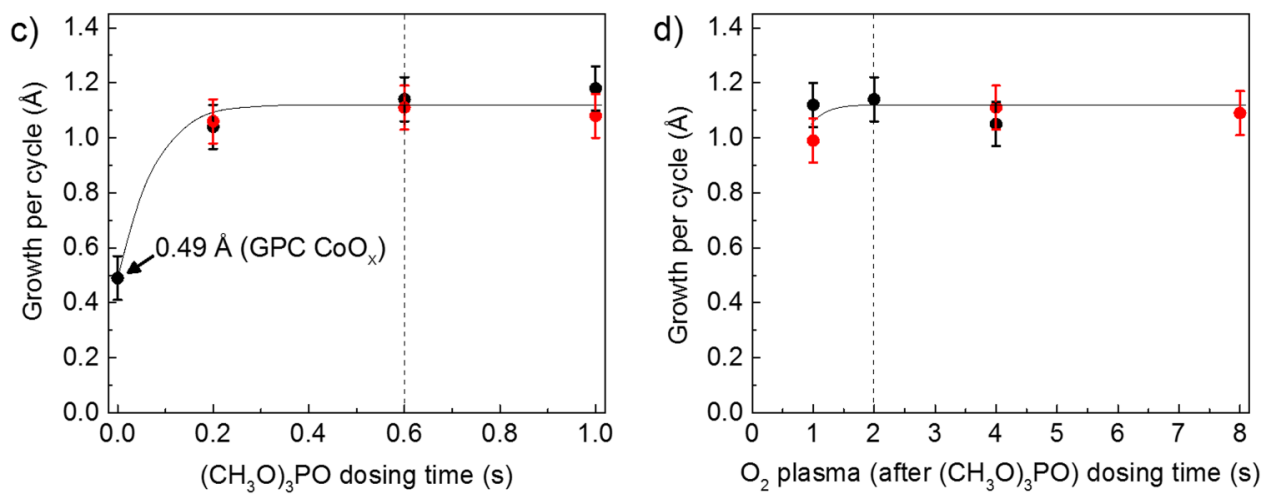
for a $\mathrm{PO}_{x}$ and $a \mathrm{CoO}_{x}$ layer, respectively. Solid lines serve as a guide to the eyes. The vertical dashed lines indicate the selected exposures for the default deposition process. The data reported have been measured at a deposition temperature of $300^{\circ} \mathrm{C}$.

\section{B. Chemical characterization}

The chemical composition of the ALD-prepared CoPi was determined by RBS and ERD, and the results are shown in Table I. The composition approaches the stoichiometry of the bulk material $\left(\mathrm{Co}_{3} \mathrm{P}_{2} \mathrm{O}_{8}\right)$, especially for the layer deposited at $200{ }^{\circ} \mathrm{C}$. Moreover, the density determined by RBS agrees well with the value of $3.8 \mathrm{~g} / \mathrm{cm}^{3}$ reported in the literature for bulk CoPi. ${ }^{35}$ The layer exhibits a negligible level of impurities in terms of hydrogen and carbon content, particularly at higher temperatures. For all the temperature range, no carbon is detected, which indicates that its concentration is below the RBS sensitivity threshold of $4 \%$ as atomic percentage. Also, XPS analysis does not show any carbon in the CoPi layer besides the adventitious carbon, which is present only at the surface. The hydrogen content is $<3 \%$ as atomic percentage for all the layers.

The effect of temperature on the ALD process was investigated at 100,200 , and $300{ }^{\circ} \mathrm{C}$, comparing the results of RBS analysis with the ex situ SE measurements. The RBS and ex situ SE results reported in Table I are consistent with each other, indicating a small decrease in the GPC when the temperature increases from 100 to $300^{\circ} \mathrm{C}$. Namely, the SE results show a decrease in GPC from 1.3 to $1.1 \AA$ when the temperature increases from 100 to $300^{\circ} \mathrm{C}$. This is different from what has been reported for ALD of other metal phosphates, generally exhibiting an increase in the GPC when temperature increases. ${ }^{15,20,22}$ The difference could be attributed to the use of a different reactant $\left(\mathrm{O}_{3}, \mathrm{H}_{2} \mathrm{O}\right.$, or a combination of them) compared to our case.
The deposition temperature also has an effect on the composition and optical properties of the layers. The change in the cobalt-to-phosphorus ratio is found to relate to the change in optical properties. The value of $n$ at $1.96 \mathrm{eV}$ shows first a decrease when the temperature is changed from 100 to $200^{\circ} \mathrm{C}$ and then again an increase at $300^{\circ} \mathrm{C}$. Since the mass density of the layers is constant within the explored temperature range, the change in $n$ can be explained considering the chemistry of the material. To address this aspect, CoPi has been regarded as the combination of $\mathrm{PO}_{\mathrm{x}}$ layers with $\mathrm{CoO}$, since as explained in the next paragraph Co is present in the oxidation state of $+2 . \mathrm{PO}_{\mathrm{x}}$ is generally reported to have values of $n$ at $1.96 \mathrm{eV}$ between 1.45 (Ref. 17) and 1.67 (Ref. 36), while for $\mathrm{CoO}, n$ is generally about $2.2 .^{37-39}$ Considering the optical properties of $\mathrm{CoO}$ and $\mathrm{PO}_{\mathrm{x}}$, we can deduce that a CoPi layer presenting a higher cobalt-to-phosphorous ratio should present higher values of $n$.

XPS analysis confirms the oxidation state of $\mathrm{Co}$ and $\mathrm{P}$ expected for CoPi. Figure 4(a) shows the Co2 $\mathrm{p}_{3 / 2}$ and Co2 $\mathrm{p}_{1 / 2}$ peaks of the ALD-prepared CoPi. The Co2 $\mathrm{p}_{3 / 2}$ peak exhibits the feature characteristic of cobalt in the oxidation state of +2 with a main component and a shoulder at higher binding energy, having approximately $50 \%$ lower intensity, which is identified as the satellite component. Furthermore, the binding energies of both the $\mathrm{Co} 2 \mathrm{p}_{3 / 2}$ and $\mathrm{Co} 2 \mathrm{p}_{1 / 2}$ components determined for ALD-prepared $\mathrm{CoPi}$ match well with the values reported in the literature for $\mathrm{CoPi}$, i.e., about $781 \mathrm{eV}$ for $\mathrm{Co} 2 \mathrm{p}_{3 / 2}$ and $797 \mathrm{eV}$ for $\mathrm{Co} 2 \mathrm{p}_{1 / 2}{ }^{40-42}$ Additionally, the P2p peak reported in Fig. 4(b) exhibits the 

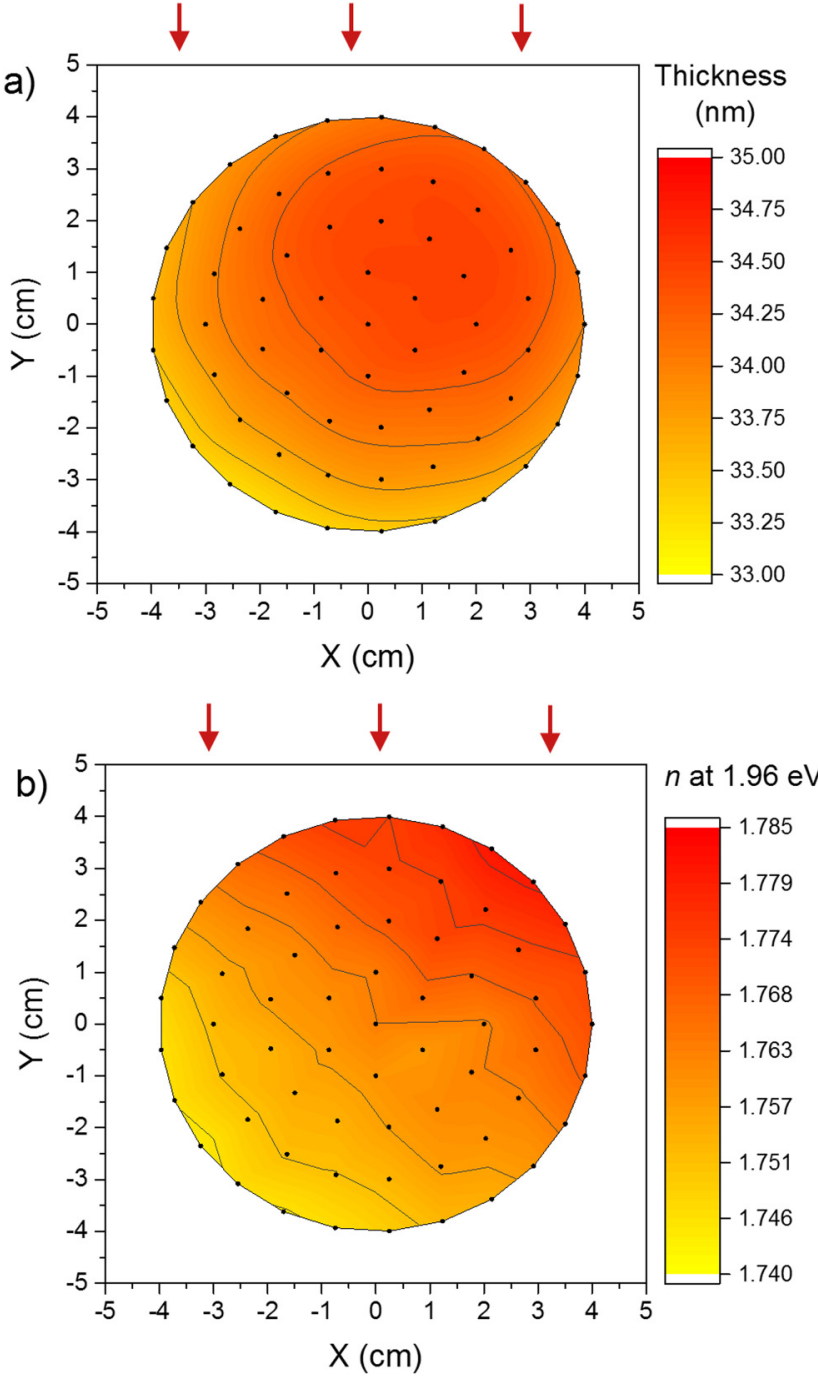

FIG. 3. Distribution of (a) thickness and (b) $n$ at $1.96 \mathrm{eV}$ for CoPi deposited on a $100-\mathrm{mm}$ c-Si wafer by 300 ALD cycles. The black dots indicate the spots for which the measurement was carried out, while the arrows on the top show the direction of the flow of the precursors. A 5-mm large circular section from the edge has been excluded from the analysis. characteristic shape and binding energy reported for CoPi in the literature. ${ }^{43}$

The crystallinity of ALD-prepared CoPi was investigated by GI-XRD. The diffraction pattern shows that the layer is amorphous (see Fig. S2 in the supplementary material ${ }^{56}$ ), as reported also for iron phosphate and titanium phosphate prepared by ALD. ${ }^{15,16}$ The broad feature in the graph, characteristic of amorphous materials, is reported also for metal phosphate glasses showing the same feature in the range between $20^{\circ}$ and $35^{\circ}$, with a shift depending on the composition of the glass. ${ }^{44,45}$

The optical properties of CoPi become relevant when using this material as a cocatalyst on the top of a photoelectrode for OER. Figures 5(a) and 5(b) show the dispersion of $k$ and $n$, respectively, determined by ex situ UV-VIS SE for the ALD-prepared $\mathrm{CoPi}$ layers. According to the fitting parameterization, the peak in the absorption coefficient is at $178 \mathrm{~nm}(7.0 \mathrm{eV})$. The value of $k$ rapidly decreases when going to higher wavelength. As expected from the Kramers-Kronig relations, the distribution of $n$ exhibits higher values close to the peak of absorption and then, at wavelengths between 210 and $1000 \mathrm{~nm}$, it decreases following a normal dispersion. The dependence of $k$ and $n$ from the deposition temperature is consistent with the behavior described above in Table I. The layer deposited at $200^{\circ} \mathrm{C}$ exhibits the lowest values of $k$ $\left(<8 \times 10^{-3}\right)$ in the visible region, while the layer deposited at $300{ }^{\circ} \mathrm{C}$ presents values of $k$ almost 1 order of magnitude higher. In view of the potential application as a cocatalyst, the composition of the layer in terms of the cobalt-to-phosphorous ratio should be taken into account, since the potential parasitic absorption in the visible region would lower the efficiency of the photoelectrode when illuminating it directly from the side of the cocatalyst.

\section{Analysis of the surface reactions}

Insight into the surface reactions taking place during ALD of CoPi has been inferred by means of QMS studies. The use of multiple pulses of precursors within one cycle has been used to gain insights into the reactivity of cobaltocene (using the "AAA-BBB-C-D" scheme) by verifying the presence of specific by-products during the multiple dosing of $\mathrm{CoCp}_{2}$. In a similar experimental setup used for QMS measurements, the reaction of cobaltocene in another plasma ALD process involves the release of one ligand as cyclopentadiene $(\mathrm{CpH}){ }^{46}$ The time-resolved measurements performed in this work (see Fig. S4 in the supplementary material ${ }^{56}$ ) do not show any increase of the signal characteristic of $\mathrm{CpH}^{+}(\mathrm{m} / z=66)$ during the

TABLE I. Areal density per ALD cycle of cobalt, phosphorus, oxygen, and hydrogen of the ALD-prepared CoPi layers, determined by RBS and ERD for different deposition temperatures. The stoichiometry is calculated by normalizing the areal density of each element by the areal density of phosphorous. The volumetric mass density is calculated from the areal densities and the thickness of the specific sample. The samples were prepared by 300 ALD cycles.

\begin{tabular}{|c|c|c|c|c|c|c|c|c|}
\hline \multirow{2}{*}{$\begin{array}{l}\mathrm{T} \\
\left({ }^{\circ} \mathrm{C}\right) \\
\end{array}$} & \multicolumn{4}{|c|}{$\begin{array}{c}\text { Areal density } \\
\left(\text { atoms } \times \mathrm{nm}^{-2} \times \text { cycle }^{-1}\right)\end{array}$} & \multirow[b]{2}{*}{ Stoichiometry } & \multirow{2}{*}{$\begin{array}{c}n \\
\text { at } 1.96 \mathrm{eV}\end{array}$} & \multirow{2}{*}{$\begin{array}{l}\text { Thickness from SE } \\
\text { (nm) }\end{array}$} & \multirow{2}{*}{$\begin{array}{l}\text { Density } \\
\left(\mathrm{g} / \mathrm{cm}^{3}\right)\end{array}$} \\
\hline & Co & $\mathrm{P}$ & $\mathrm{O}$ & $\mathrm{H}$ & & & & \\
\hline 100 & $2.56 \pm 0.07$ & $1.49 \pm 0.07$ & $6.8 \pm 0.3$ & $0.33 \pm 0.07$ & $\mathrm{Co}_{3.4} \mathrm{P}_{2} \mathrm{O}_{9.1}$ & $1.81 \pm 0.01$ & $40 \pm 2$ & $3.9 \pm 0.2$ \\
\hline 200 & $2.13 \pm 0.07$ & $1.39 \pm 0.03$ & $5.8 \pm 0.3$ & $0.08 \pm 0.01$ & $\mathrm{Co}_{3.1} \mathrm{P}_{2} \mathrm{O}_{8.3}$ & $1.75 \pm 0.01$ & $35 \pm 2$ & $3.8 \pm 0.2$ \\
\hline 300 & $2.07 \pm 0.07$ & $1.24 \pm 0.03$ & $5.3 \pm 0.3$ & $0.10 \pm 0.02$ & $\mathrm{Co}_{3.3} \mathrm{P}_{2} \mathrm{O}_{8.5}$ & $1.78 \pm 0.01$ & $33 \pm 2$ & $3.8 \pm 0.2$ \\
\hline
\end{tabular}



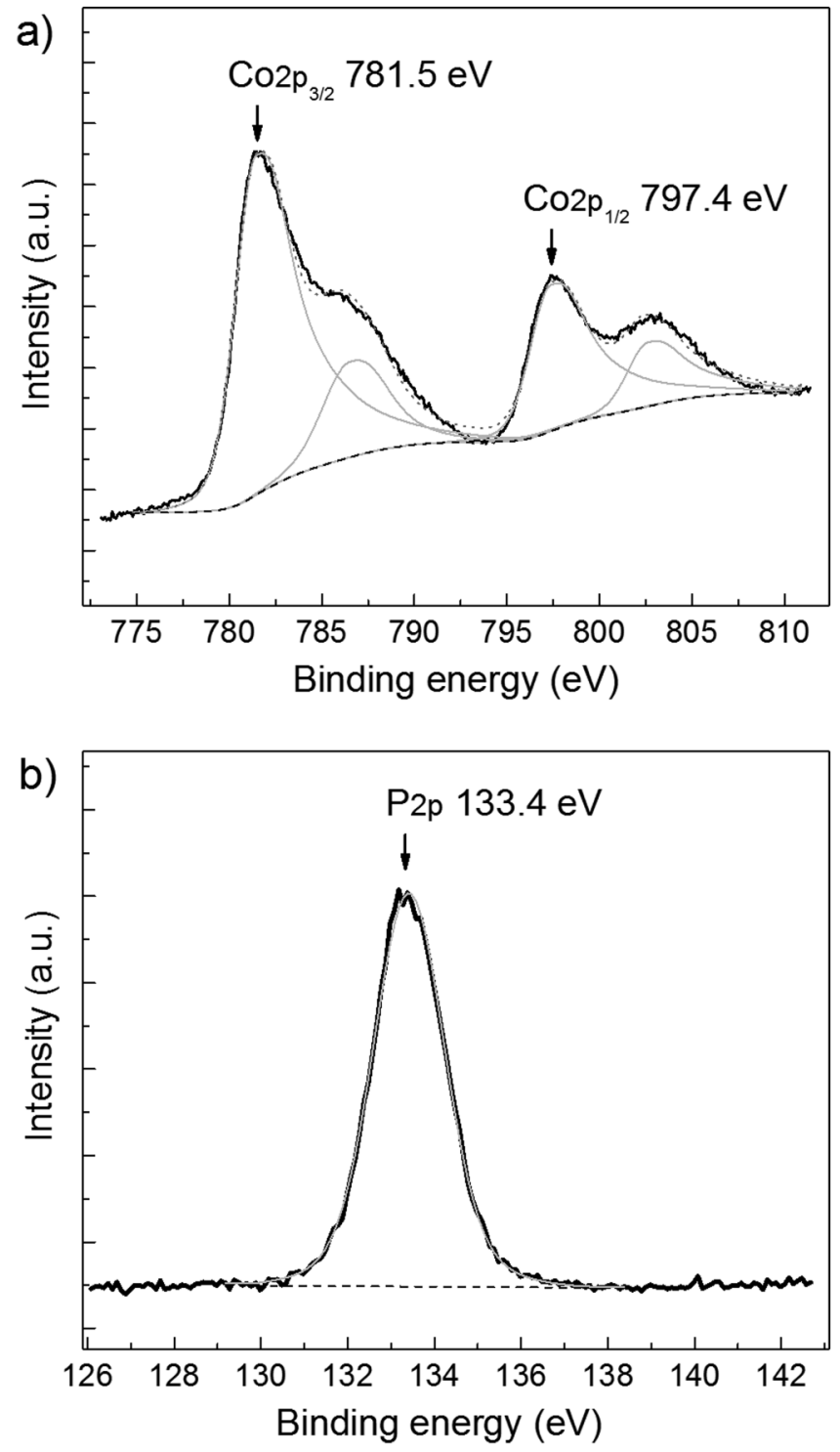

FIG. 4. XPS spectra of (a) Co2p peak and (b) P2p peak of a 67-nm thick CoPi layer, prepared at $300^{\circ} \mathrm{C}$ by ALD.

sequential dosing of $\mathrm{CoCp}_{2}$. At the same time, we have been able to measure the small increase in the signal characteristic of the precursor (see Fig. S5 in the supplementary material ${ }^{56}$ ) due to the saturation of the surface sites. Considering also that upon investigation it was found no evidence of the formation of other by-products during $\mathrm{CoCp}_{2}$ dosing (see Fig. S6 in the supplementary material $^{56}$ ), we suggest that the pathway of reaction for step A is likely to be the associative adsorption of $\mathrm{CoCp}_{2}$ at the surface without any exchange of ligands.

The subsequent $\mathrm{O}_{2}$ plasma step removes the $\mathrm{Cp}$ ligands from the precursor adsorbed at the surface through combustionlike
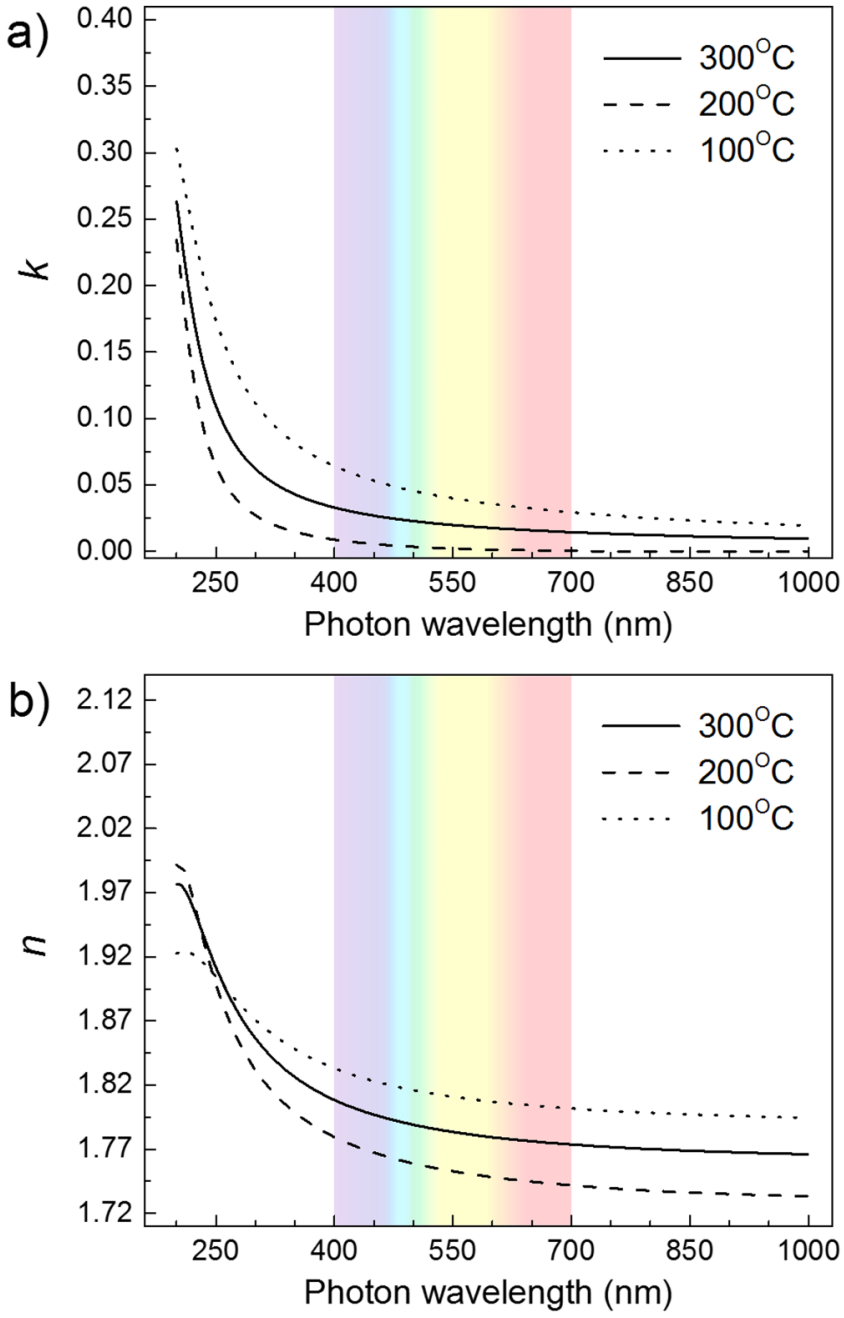

FIG. 5. Dispersion of (a) $k$ and (b) $n$ determined by fitting of the ex situ UV-VIS SE measurements with a Tauc-Lorentz oscillator for the CoPi layers deposited at 100,200 , and $300{ }^{\circ} \mathrm{C}$. The visible region of the spectrum has been highlighted.

reactions. Figure 6 highlights the formation of the typical by-products of combustion showing the signals of $\mathrm{H}_{2} \mathrm{O}^{+}$[Fig. 6(a)], $\mathrm{CO}^{+}$[Fig. 6(b)], and $\mathrm{CO}_{2}^{+}$[Fig. 6(c)] during the sequential exposure to $\mathrm{O}_{2}$ plasma after $\mathrm{CoCp}_{2}$ dosing. The amount of those by-products generated in the plasma exposure shows a major decrease after the first pulse, yet a small component is present in the subsequent pulses probably due to further removal of ligands from the wall of the reactor. It is worth to mention that a major fraction of the $\mathrm{CO}^{+}$detected is actually generated as $\mathrm{CO}$ inside the ALD chamber and not from the dissociation of $\mathrm{CO}_{2}$ in the ionization source of the mass spectrometer (see Sec. "IV.a." of the supplementary material ${ }^{56}$ ).

In order to shed light on the initial steps of the Cp removal by the $\mathrm{O}_{2}$ plasma, we had a closer look at the first $\mathrm{O}_{2}$ plasma pulse of 


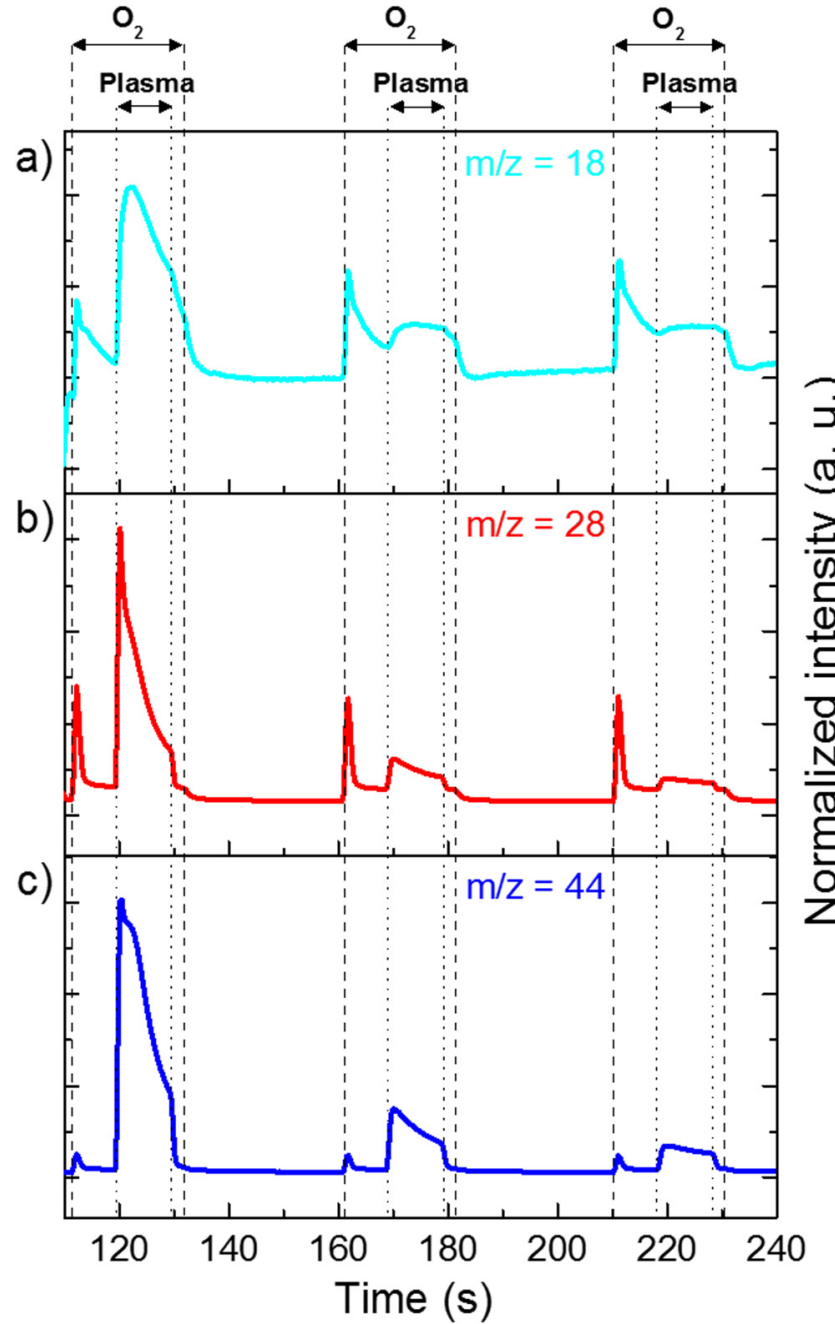

FIG. 6. Time-resolved QMS measurements of the $m / z$ indicative of (a) $\mathrm{H}_{2} \mathrm{O}^{+}$ $(\mathrm{m} / \mathrm{z}=18)$, (b) $\mathrm{CO}^{+}(\mathrm{m} / \mathrm{z}=28)$, and (c) $\mathrm{CO}_{2}^{+}(\mathrm{m} / \mathrm{z}=44)$ during sequential $\mathrm{O}_{2}$ plasma exposures after $\mathrm{CoCp}_{2}$ dosing. The by-products detected indicate a combustionlike reaction during the $\mathrm{O}_{2}$ plasma step after $\mathrm{CoCp}_{2}$ dosing.

the series, by analyzing different $m / z$ values. As reported in Fig. 7, the plasma ignition is suddenly followed by the generation of species with $\mathrm{m} / z 26$ and 52 that can be attributed to the ionization of vinyl acetylene $\left(\mathrm{C}_{4} \mathrm{H}_{4}\right)$ and acetylene $\left(\mathrm{C}_{2} \mathrm{H}_{2}\right)$. As a matter of fact, both experimental and computational studies ${ }^{47-49}$ report $\mathrm{C}_{2} \mathrm{H}_{2}$, $\mathrm{C}_{4} \mathrm{H}_{4}$, and $\mathrm{CO}$ as by-products of the oxidation of the $\mathrm{Cp}$ through the reaction pathway that produces cyclopentadienone $\left(\mathrm{C}_{5} \mathrm{H}_{4} \mathrm{O}\right)$ as intermediate. Nevertheless, no signal of $\mathrm{C}_{5} \mathrm{H}_{4} \mathrm{O}^{+}$has been detected. We then suggest that the removal of $\mathrm{Cp}$ ligands occurs through the oxidation via plasma of the $\mathrm{Cp}$ to $\mathrm{C}_{5} \mathrm{H}_{4} \mathrm{O}$, which subsequently dissociates in the reactor generating $\mathrm{C}_{4} \mathrm{H}_{4}, \mathrm{C}_{2} \mathrm{H}_{2}$, and $\mathrm{CO}$. Then, the signals of the $\mathrm{C}_{4} \mathrm{H}_{4}^{+}$and $\mathrm{C}_{2} \mathrm{H}_{2}^{+}$are detected only in the initial stage of the $\mathrm{O}_{2}$ plasma step, i.e., within $2 \mathrm{~s}$ after plasma ignition, since

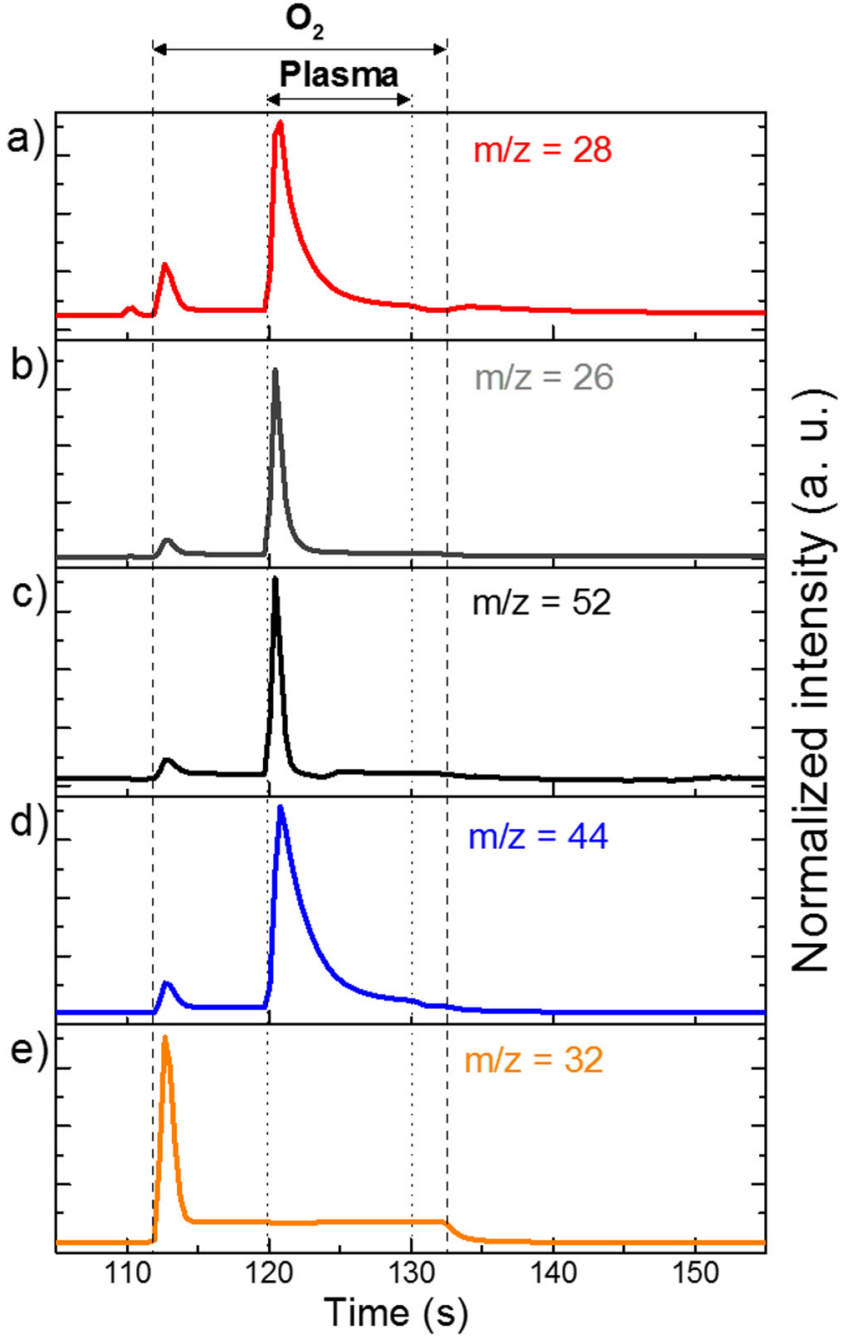

FIG. 7. Time-resolved QMS measurements of (a) $\mathrm{CO}^{+}(\mathrm{m} / \mathrm{z}=28)$, (b) $\mathrm{C}_{2} \mathrm{H}_{2}^{+}(\mathrm{m} /$ $z=26)$, (c) $\mathrm{C}_{4} \mathrm{H}_{4}^{+}(\mathrm{m} / \mathrm{z}=52)$, (d) $\mathrm{CO}_{2}^{+}(\mathrm{m} / \mathrm{z}=44)$, and (e) $\mathrm{O}_{2}^{+}(\mathrm{m} / \mathrm{z}=32)$ during $\mathrm{O}_{2}$ plasma after the $\mathrm{CoCp}_{2}$ dosing.

$\mathrm{C}_{4} \mathrm{H}_{4}$ and $\mathrm{C}_{2} \mathrm{H}_{2}$ undergo oxidation, producing $\mathrm{CO}, \mathrm{CO}_{2}$, and $\mathrm{H}_{2} \mathrm{O}$. Accordingly, the signals of $\mathrm{CO}^{+}$and $\mathrm{CO}_{2}^{+}$show a tail for longer plasma exposure, indicating the continuation of the oxidation reaction. Further investigation would be necessary to determine if the dissociation of $\mathrm{C}_{5} \mathrm{H}_{4} \mathrm{O}$ takes place at the surface or in the gas phase.

The TMP dosing, different from the $\mathrm{CoCp}_{2}$ dosing, is characterized by the chemisorption of the molecule followed by ligand elimination. Figure 8 reports the reaction mechanism proposed for the adsorption of TMP on the surface. The mechanism is based on the electrophilic attack of dimethyl methyl phosphonate on a metal oxide surface reported in the literature, ${ }^{50-52}$ and it considers a similar reactivity for TMP. The chemisorption proceeds via bonding between the terminal oxygen of the $\mathrm{P}=\mathrm{O}$ group and the 


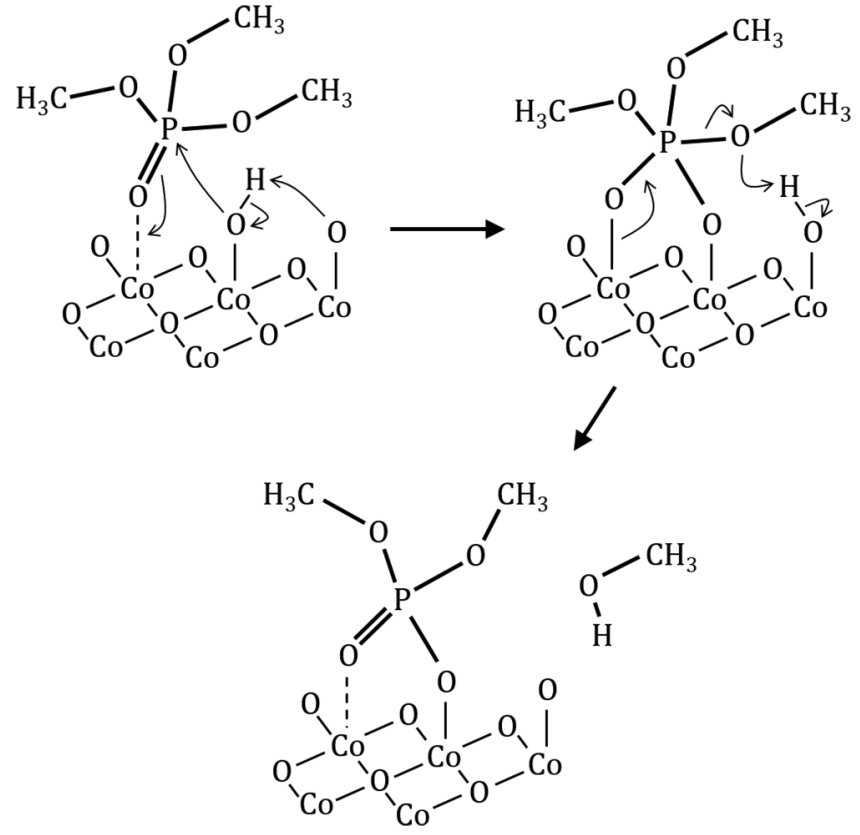

FIG. 8. Reaction mechanism proposed for the chemisorption of TMP on the surface. Each curved arrow shows the transfer of an electron pair.

under-coordinated cobalt atoms at the surface. The reaction proceeds further with phosphorus bonding to the oxygen at the surface, followed by elimination of a methanol molecule.

The generation of methanol according to the above-mentioned mechanism has been verified by QMS measurements, applying the multipulse approach (scheme "A-B-CCC-DDD"). The results reported in Fig. 9 show that the intensity of the $\mathrm{m} / \mathrm{z}$ attributed to TMP (95 and 79 for $\mathrm{PO}_{3} \mathrm{CH}_{4}^{+}$and $\mathrm{PO}_{3}^{+}$fragments, respectively ${ }^{53}$ ) increase, while the intensity of the $\mathrm{m} / z$ attributed to methanol (32 and 29 for the parent ion $\mathrm{CH}_{3} \mathrm{OH}^{+}$and the $\mathrm{OCH}^{+}$fragment, respectively $^{54}$ ) decrease. This is in line with the saturation of the surface sites, resulting in an increase in the amount of precursor and a decrease in the amount of by-products reaching the mass spectrometer, confirming the role of methanol as by-product of the reaction.

In addition, the role of the surface composition in the reactivity of TMP has been highlighted. Figures 9(a) and 9(b) show the comparison between the reactivity of TMP on a $\mathrm{CoO}_{\mathrm{x}}$ terminated surface (solid lines) and on a $\mathrm{PO}_{\mathrm{x}}$ terminated surface (dashed lines). As mentioned previously in the discussion of $\mathrm{CoCp}_{2}$ dosing [Fig. 2(a)], the GPC of a $\mathrm{PO}_{\mathrm{x}}$ layer is negligible under these experimental conditions, indicating that the presence of a $\mathrm{CoO}_{\mathrm{x}}$ terminated substrate is essential for TMP in order to react quantitatively. In agreement with those findings, when the ALD process has been modified by removing the $\mathrm{CoO}_{\mathrm{x}}$ step (using the "CCC-DDD" scheme), a higher amount of TMP fragments has been detected by the mass spectrometer [dashed lines in Figs. 9(a) and 9(b)] indicating that the consumption of TMP has been inhibited.

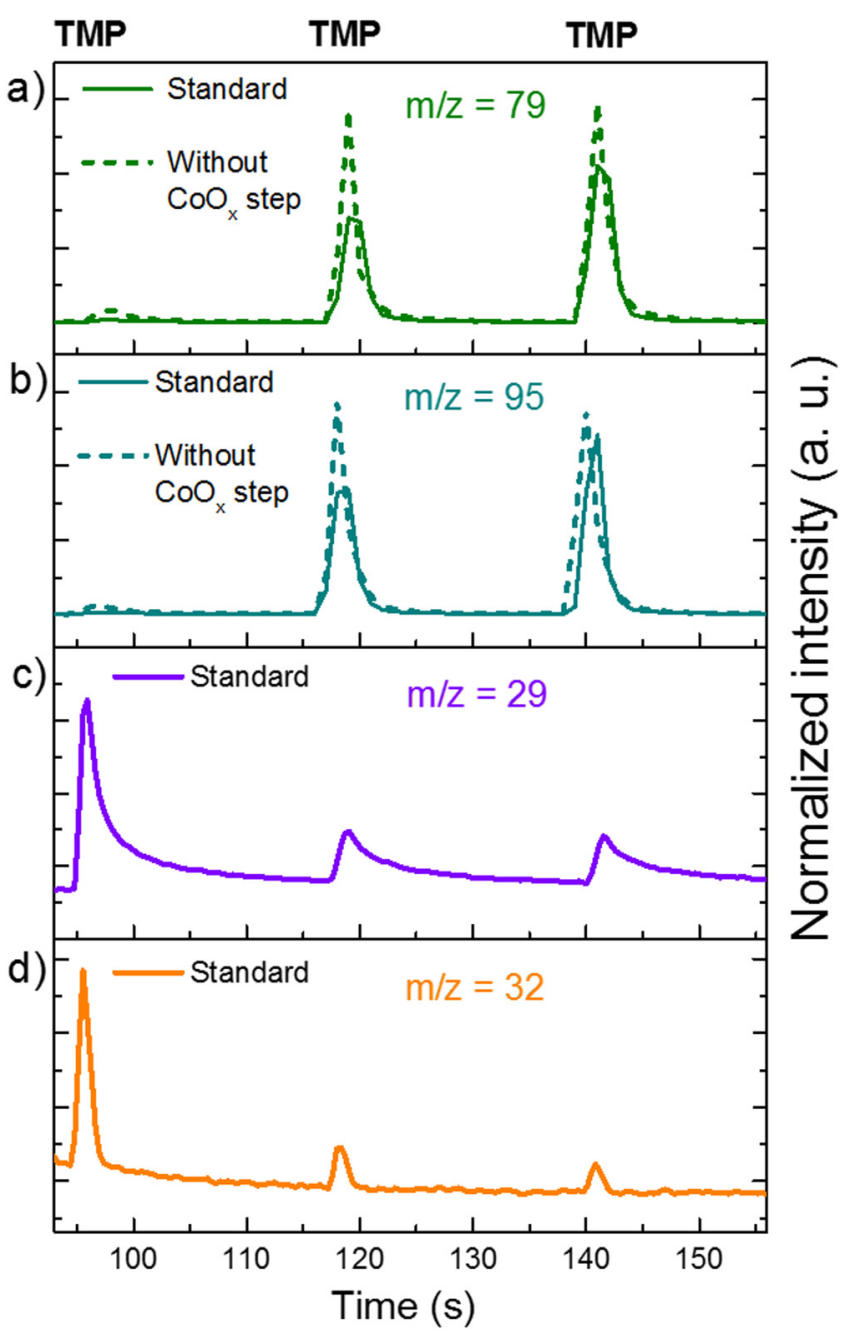

FIG. 9. Time-resolved QMS data for the multipulse of TMP, for the standard ALD process (solid line), and the process without the $\mathrm{CoO}_{x}$ step (dashed line). The $\mathrm{m} / \mathrm{z}$ values selected are indicative of (a) $\mathrm{PO}_{3}^{+}$and (b) $\mathrm{PO}_{3} \mathrm{CH}_{4}^{+}$fragments derived from TMP and (c) $\mathrm{CH}_{3} \mathrm{OH}^{+}$parent ion and (d) $\mathrm{OCH}^{+}$fragment derived from methanol.

Figure 10 shows the results of time-resolved QMS measurements during the overall ALD cycle. From Figs. 10(b) and 10(c), it is possible to notice the peaks associated with the production of $\mathrm{CO}_{2}$ and $\mathrm{CO}$ during the $\mathrm{O}_{2}$ plasma exposure after the TMP dosing, indicating that the removal of the remaining TMP ligands occurs through a combustionlike reaction.

The surface reactions proposed seem to be consistent with the different plasma exposure times needed to achieve saturation, namely, $5 \mathrm{~s}$ after $\mathrm{CoCp}_{2}$ dosing and $2 \mathrm{~s}$ after TMP dosing, since a longer plasma exposure can be necessary to oxidize and remove ligands having a higher number of carbon atoms. Further indications on the surface reactions proposed above can be deduced from the overall ALD cycle, comparing the two $\mathrm{O}_{2}$ plasma steps 


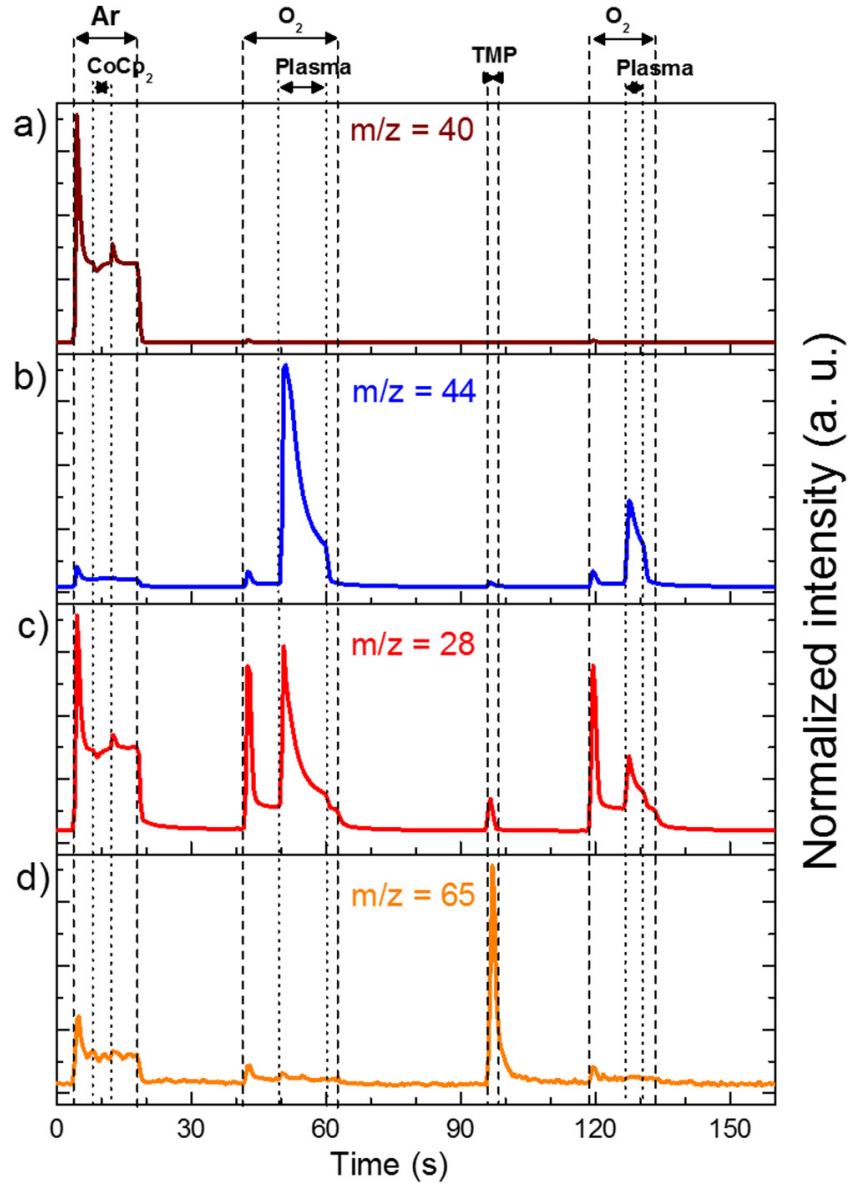

FIG. 10. Time-resolved QMS measurements during ALD of CoPi, reporting $\mathrm{m} / \mathrm{z}$ of (a) $\mathrm{Ar}^{+}(\mathrm{m} / \mathrm{z}=40)$, (b) $\mathrm{CO}_{2}^{+}(\mathrm{m} / \mathrm{z}=44),(\mathrm{c}) \mathrm{CO}^{+}(\mathrm{m} / \mathrm{z}=28)$, and (d) the $\mathrm{P}(\mathrm{OH})_{2}^{+}$ fragment $(m / z=65)$ characteristic of TMP (Ref. 55).

[Figs. 10(b) and $10(\mathrm{c})$ ]. By integration of the area under the respective $\mathrm{m} / z$ curve (see Figs. S8 and S9 in the supplementary material ${ }^{56}$ ), we can compare the relative amount of $\mathrm{CO}_{2}$ and $\mathrm{CO}$ produced during the two $\mathrm{O}_{2}$ plasma steps [Figs. 10(b) and 10(d)]. That amount should be proportional to the number of carbon atoms present in the ligands after adsorption of each precursor. In the specific case, after associative adsorption of $\mathrm{CoCp}_{2}$, a total of 10 carbon atoms are present in the ligands while after the chemisorption of TMP, the number of carbon atoms in the ligands is 2 . The amounts of $\mathrm{CO}_{2}$ and $\mathrm{CO}$ produced in step $\mathrm{B}$ is almost five times higher than the amounts produced in step $\mathrm{D}$, in line with the proportion between the numbers of carbon atoms present in the ligands for the reactions proposed. Nevertheless, the precise quantification is not trivial, and it should take into account the different coverage of the precursors and the major contribution to the signal detected given by the process occurring at the wall of the reactor, which can be outside the saturation regime for the $\mathrm{O}_{2}$ plasma step.

\section{SUMMARY AND CONCLUSIONS}

Plasma-assisted ALD of CoPi has been performed using $\mathrm{CoCp}_{2}$ and TMP as precursors and $\mathrm{O}_{2}$ plasma as a reactant according to an $\mathrm{ABCD}$ process scheme. The adoption of TMP exposure followed by $\mathrm{O}_{2}$ plasma for incorporation of the phosphate has been successful, and the process characteristics have been studied. The ALD process shows a GPC of $1.12 \pm 0.05 \AA$ at $300^{\circ} \mathrm{C}$, a linear growth, and no nucleation delay. The self-limiting behavior of each step has been demonstrated by determination of the saturation curves. The process exhibits good uniformity in terms of thickness and refractive index at $1.96 \mathrm{eV}$, resulting in being suitable for the potential application on electrodes or photoelectrodes of size up to $100 \mathrm{~mm}$ in diameter.

The ALD-prepared CoPi layers present a composition close to the stoichiometric state, especially for the layer deposited at $200{ }^{\circ} \mathrm{C}$ $\left(\mathrm{Co}_{3.1} \mathrm{P}_{2} \mathrm{O}_{8.3}\right)$. This is quite exceptional compared to the main literature on ALD of transition metal phosphates, often reporting the use of supercycles to adjust the stoichiometry. Moreover, the density of the layers and the chemical state of cobalt and phosphorus are in agreement with those of the literature on $\mathrm{CoPi}$. The optochemical properties of the layers have been studied as a function of the deposition temperature, and it has been found that the cobaltto-phosphorus ratio relates to the optical behavior. The latter has been addressed comparing the values of $n$ reported for $\mathrm{PO}_{\mathrm{x}}$ (between 1.45 and 1.67) and $\mathrm{CoO}$ (about 2.2). Those values can explain the higher refractive index of the CoPi layers presenting higher cobalt-to-phosphorus ratios. Similar dependence from deposition temperature and composition has been found for the values of $k$, which exhibits a peak at $178 \mathrm{~nm}(7.0 \mathrm{eV})$ and decreases for higher wavelengths. The distribution of $n$ is consistent with the distribution of $k$ according to the Kramers-Kroning relations, showing higher values close to the peak of absorption and decreasing at higher wavelengths, following a normal distribution between 210 and $1000 \mathrm{~nm}$. In view of the application of the layers as a cocatalyst, the CoPi deposited at $200{ }^{\circ} \mathrm{C}$ is the most suitable in terms of optical properties, with values of $k<8 \times 10^{-3}$ in the visible region.

Insight into the surface reactions occurring during the ALD process has been deduced from mass spectrometry investigations for each ALD step. The $\mathrm{CoCp}_{2}$ dosing is characterized by the absence of by-products, indicating that the adsorption of the precursor on the surface is likely to occur without ligand exchange. Then the subsequent $\mathrm{O}_{2}$ plasma exposure removes the $\mathrm{Cp}$ ligands via combustionlike reactions, as revealed by detection of $\mathrm{CO}_{2}^{+}, \mathrm{CO}^{+}$, and $\mathrm{H}_{2} \mathrm{O}^{+}$. Moreover, through the identification of the $\mathrm{C}_{4} \mathrm{H}_{4}^{+}$and $\mathrm{C}_{2} \mathrm{H}_{2}^{+}$species in the initial stage of the plasma step, we have indirect evidence on the basis of the literature that the formation of $\mathrm{C}_{5} \mathrm{H}_{4} \mathrm{O}$ is a step involved in the oxidation and removal of the $\mathrm{Cp}$. Differently from the $\mathrm{CoCp}_{2}$ dosing, the TMP dosing is characterized by chemisorption on the substrate via elimination of one methanol molecule. Then the conversion of the remaining ligands is performed through the oxidation via the $\mathrm{O}_{2}$ plasma exposure. The surface reactions suggested are in line with the relative amount of $\mathrm{CO}_{2}$ and $\mathrm{CO}$ produced during the two $\mathrm{O}_{2}$ plasma steps. The overall ALD process presented is dominated by the removal of ligands through the exposure to $\mathrm{O}_{2}$ plasma. This can possibly explain the quality of the material prepared 
in terms of impurities, since no carbon has been detected and the hydrogen content stays below 3 at. \% for all the layers deposited.

\section{ACKNOWLEDGMENTS}

The authors acknowledge the TU/e-DIFFER impulse program for financial support and Oxford Instruments and thank Yi Shu for the uniformity measurements, Cristian A. A. van Helvoirt for the GI-XRD measurements, and Caspar O. van Bommel, Joris J. L. M. Meulendijks, and Janneke J. A. Zeebregts for technical support.

\section{REFERENCES}

${ }^{1}$ R. L. Doyle, I. J. Godwin, M. P. Brandon, and M. E. G. Lyons, Phys. Chem. Chem. Phys. 15, 13737 (2013).

${ }^{\mathbf{2}}$ S. Anantharaj, S. R. Ede, K. Sakthikumar, K. Karthick, S. Mishra, and S. Kundu, ACS Catal. 6, 8069 (2016).

${ }^{3}$ A. Kudo and Y. Miseki, Chem. Soc. Rev. 38, 253 (2009).

${ }^{4}$ J. Barber, Chem. Soc. Rev. 38, 185 (2009).

${ }^{5}$ D. Gust, T. A. Moore, and A. L. Moore, Acc. Chem. Res. 42, 1890 (2009).

${ }^{6}$ H. Kim, J. Park, I. Park, K. Jin, S. E. Jerng, S. H. Kim, K. T. Nam, and K. Kang, Nat. Commun. 6, 8253 (2015).

${ }^{7}$ M. W. Kanan and D. G. Nocera, Science 321, 1072 (2008).

${ }^{8}$ Y. Surendranath, M. W. Kanan, and D. G. Nocera, J. Am. Chem. Soc. 132, 16501 (2010).

${ }^{9} \mathrm{~K}$. Klingan, F. Ringleb, I. Zaharieva, J. Heidkamp, P. Chernev, D. Gonzalez-Flores, M. Risch, A. Fischer, and H. Dau, ChemSusChem 7, 1301 (2014).

${ }^{10}$ M. Barroso, A. J. Cowan, S. R. Pendlebury, M. Gratzel, D. R. Klug, and J. R. Durrant, J. Am. Chem. Soc. 133, 14868 (2011).

${ }^{11}$ R. W. Johnson, A. Hultqvist, and S. F. Bent, Mater. Today 17, 236 (2014).

${ }^{12}$ C. Marichy, M. Bechelany, and N. Pinna, Adv. Mater. 24, 1017 (2012).

${ }^{13}$ S. M. George, Chem. Rev. 110, 111 (2010).

${ }^{14}$ V. Di Palma, G. Zafeiropoulos, T. Goldsweer, W. M. M. Kessels, M. C. M. van de Sanden, M. Creatore, and M. N. Tsampas, Electrochem. Commun. 98, 73 (2019).

${ }^{15}$ K. B. Gandrud, A. Pettersen, O. Nilsen, and H. Fjellvåg, J. Mater. Chem. A 1, 9054 (2013).

${ }^{16}$ T. Dobbelaere, F. Mattelaer, A. K. Roy, P. Vereecken, and C. Detavernier, J. Mater. Chem. A 5, 330 (2017).

17. Ludwig and T. Nilges, J. Power Sources 382, 101 (2018).

${ }^{18} \mathrm{~J}$. Ni, L. Gao, and L. Lu, J. Power Sources 221, 35 (2013).

${ }^{19}$ I. C. Jang, H. H. Lim, S. B. Lee, K. Karthikeyan, V. Aravindan, K. S. Kang, W. S. Yoon, W. I. Cho, and Y. S. Lee, J. Alloys Compd. 497, 321 (2010).

${ }^{20} \mathrm{~J}$. Hämäläinen, J. Holopainen, F. Munnik, M. Heikkilä, M. Ritala, and M. Leskelä, J. Phys. Chem. C 116, 5920 (2012).

${ }^{21}$ T. Dobbelaere, A. K. Roy, P. Vereecken, and C. Detavernier, Chem. Mater. 26, 6863 (2014).

${ }^{22}$ M. Putkonen, T. Sajavaara, P. Rahkila, L. Xu, S. Cheng, L. Niinistö, and H. J. Whitlow, Thin Solid Films 517, 5819 (2009).

${ }^{23}$ J. Hamalainen, J. Holopainen, F. Munnik, T. Hatanpaa, M. Heikkila, M. Ritala, and M. Leskela, J. Electrochem. Soc. 159, A259 (2012).

${ }^{24}$ B. Wang, J. Liu, Q. Sun, R. Li, T. K. Sham, and X. Sun, Nanotechnology 25, 504007 (2014).

${ }^{25}$ M. K. Wiedmann, D. H. K. Jackson, Y. J. Pagan-Torres, E. Cho, J. A. Dumesic, and T. F. Kuech, J. Vac. Sci. Technol. A 30, 101A134 (2012).

${ }^{\mathbf{2 6}}$ H. H. Sønsteby, E. Østreng, H. Fjellvåg, and O. Nilsen, Chem. Vap. Deposit. 20, 269 (2014).
${ }^{\mathbf{2 7}}$ T. Dobbelaere, M. Minjauw, T. Ahmad, P. M. Vereecken, and C. Detavernier, J. Non-Cryst. Solids 444, 43 (2016).

${ }^{28}$ J. Ronge, T. Dobbelaere, L. Henderick, M. M. Minjauw, S. P. Sree, J. Dendooven, J. A. Martens, and C. Detavernier, Nanoscale Adv. 1, 4166 (2019).

${ }^{29}$ M. E. Donders, H. C. M. Knoops, M. C. M. van de Sanden, W. M. M. Kessels, and P. H. L. Notten, J. Electrochem. Soc. 158, G92 (2011).

${ }^{30}$ H. C. M. Knoops, A. J. M. Mackus, M. E. Donder, M. C. M. van de Sanden, P. H. L. Notten, and W. M. M. Kessels, Electrochem. Solid-State Lett. 12, G34 (2009).

${ }^{31}$ S. B. S. Heil, E. Langereis, F. Roozeboom, M. C. M. van de Sanden, and W. M. M. Kessels, J. Electrochem. Soc. 153, G956 (2006).

${ }^{32}$ A. V. Shchukarev and D. V. Korolkov, Open Chem. 2, 347 (2004).

${ }^{33}$ Y. Snoussi, A. M. Khalil, B. Strzemiecka, A. Voelkel, and M. M. Chehimi, in Clay-Polymer Nanocomposites, edited by K. Jlassi, M. M. Chehimi, S. Thomas (Elsevier, Amsterdam, 2017), Chap. 11, pp. 363-411.

${ }^{34}$ V. Vandalon and W. M. M. Kessels, J. Vac. Sci. Technol. A 35, 05 C313 (2017).

${ }^{35}$ J. B. Anderson, E. Kostiner, M. C. Miller, and J. R. Rea, J. Solid State Chem. 14, 372 (1975).

${ }^{36}$ L. E. Black, A. Cavalli, M. A. Verheijen, J. E. M. Haverkort, E. P. A. M. Bakkers, and W. M. M. Kessels, Nano Lett. 17, 6287 (2017).

${ }^{37}$ E. Amin-Chalhoub, T. Duguet, D. Samélor, O. Debieu, E. Ungureanu, and C. Vahlas, Appl. Surf. Sci. 360, 540 (2016).

${ }^{38}$ D. Gallant, M. Pézolet, and S. Simard, J. Phys. Chem. B 110, 6871 (2006).

${ }^{39}$ B. Vitt, Sol. Energy Mater. 19, 131 (1989).

${ }^{40}$ M. C. Biesinger, B. P. Payne, A. P. Grosvenor, L. W. M. Lau, A. R. Gerson, and R. St. C. Smart, Appl. Surf. Sci. 257, 2717 (2011).

${ }^{41}$ Y. P. Zhu, T. Z. Ren, and Z. Y. Yuan, Nanoscale 6, 11395 (2014).

${ }^{42} \mathrm{G}$. Ai, R. Mo, H. Li, and J. Zhong, Nanoscale 7, 6722 (2015).

${ }^{43}$ B. Senthilkumar, Z. Khan, S. Park, I. Seo, H. Ko, and Y. Kim, J. Power Sources 311, 29 (2016).

${ }^{44}$ A. M. Abdelghany, G. El-Damrawi, Oraby, and M. A. Madshal, J. Non-Cryst. Solids 499, 153 (2018).

${ }^{45}$ M. A. Ghauri, S. A. Siddiqi, W. A. Shah, M. G. B. Ashiq, and M. Iqbal, J. Non-Cryst. Solids 355, 2466 (2009).

${ }^{46}$ M. F. J. Vos, G. van Straaten, W. M. M. Erwin Kessels, and A. J. M. Mackus, J. Phys. Chem. C 122, 22519 (2018).

${ }^{47}$ R. K. Robinson and R. P. Lindstedt, Combust. Flame 158, 666 (2011).

${ }^{48}$ A. Ristori, P. Dagaut, A. El Bakali, G. Pengloan, and M. Cathonnet, Combust. Sci. Technol. 167, 223 (2001).

${ }^{49} \mathrm{M}$. U. Alzueta, P. Glarborg, and K. Dam-Johansen, Int. J. Chem. Kinet. 32, 498 (2000).

${ }^{50}$ M. B. Mitchell, V. N. Sheinker, and E. A. Mintz, J. Phys. Chem. B 101, 11192 (1997).

${ }^{51}$ V. Štengl, J. Henych, T. Grygar, and R. Peréz, Mater. Res. Bull. 61, 259 (2015).

52D. A. Panayotov and J. R. Morris, Langmuir 25, 3652 (2009).

${ }^{53}$ D. Z. Brunengraber, B. J. McCabe, J. Katanik, and S. F. Previs, Anal. Biochem. 306, 278 (2002).

${ }^{54}$ NIST Mass Spectrometry Data Center, William E. Wallace, "Mass spectra," in NIST Chemistry WebBook, NIST Standard Reference Database Number 69, edited by P.J. Linstrom and W.G. Mallard (National Institute of Standards and Technology, Gaithersburg, MD), p. 20899, see https://doi.org/10.18434/T4D303 (retrieved August 26, 2019).

${ }^{55}$ R. Srikanth, R. Srinivas, K. Bhanuprakash, S. Vivekananda, E. A. Syrstad, and F. Tureček, J. Am. Soc. Mass Spectrom. 13, 250 (2002).

${ }^{56}$ See supplementary material at https://doi.org/10.1116/1.5143896 for in situ spectroscopic ellipsometry, GI-XRD diffraction pattern, SEM images, and timeresolved QMS data. 